\title{
GOVERNANÇA E PLANEJAMENTO DE TECNOLOGIA DA INFORMAÇÃO: UM ESTUDO EXPLORATÓRIO DA PRODUÇÃO STRICTO SENSU NO BRASIL ENTRE 1995 E 2014
}

INFORMATION TECHNOLOGY GOVERNANCE AND INFORMATION TECHNOLOGY PLANNING: AN EXPLORATORY STUDY OF DOCTORATE AND MASTER DEGREES PRODUCTION IN BRAZIL BETWEEN 1995 AND 2014

\author{
FÁBIO LUÍS FALCHI DE MAGALHÃES ${ }^{1}$ \\ FÁBIO KAZUO OHASHI ${ }^{2}$ \\ LIDIANE CRISTINA DA SILVA ${ }^{3}$ \\ MARCOS ANTONIO GASPAR ${ }^{4}$ \\ MARCOS VINICIUS CARDOSO
}

\begin{abstract}
RESUMO: O objetivo desta pesquisa é o de explorar a produção científica no Brasil sobre a temática governança e planejamento de TI, a partir das dissertações e teses publicadas no país provenientes de cursos de pós-graduação stricto sensu, no período de 1995 a 2014. Esta temática se destacou em 2012 como uma das maiores preocupações da gestão nas organizações no mundo segundo a 'Society for Information Management'. É realizada uma pesquisa descritiva documental com a utilização da bibliometria, tendo como base de dados à plataforma CNPq Lattes. Foram identificados 263 trabalhos, sendo 34 (D), 160 (ME) e 69 (MP). Com 259 egressos, 104 programas em 67 diferentes IES e 176 orientadores, mais da metade dos trabalhos são oriundos de programas de excelente qualidade (sem MP). Maioria das instituições e pesquisadores, igualmente participando em congressos científicos específicos refletindo avanço na área. IES particulares sem fins lucrativos, o Sudeste, o estado de São Paulo, a Universidade Católica de Brasília (UCB) e João Souza Neto foram os mais profícuos. A temática analisada tem sido assunto de interesse de pesquisa, notadamente pelo pleno crescimento no decorrer do período analisado, com destaque para o ano 2012 e categoria temática governança de TI. Metade dos estudos tem sido realizada na área da Administração, Ciências Contábeis e Turismo, mas também se verificou a ocorrência de trabalhos nas áreas: Engenharias III, Interdisciplinar, Ciência da Computação e Engenharias IV, entre outras, de um total de dez das 48 áreas de avaliação da CAPES.
\end{abstract}

Palavras-chave: Produção científica. Governança de tecnologia da informação. Planejamento de tecnologia da informação.

\footnotetext{
Data de submissão: 23/08/2016 Data de aceite: 19/02/2018 Data de publicação:

${ }^{1}$ Professor da diretoria de Informática e doutorando em Informática e Gestão do Conhecimento da Universidade Nove de Julho (UNINOVE)

${ }^{2}$ Professor da diretoria de Informática e mestrando em Informática e Gestão do Conhecimento da Universidade Nove de Julho (UNINOVE)

${ }^{3}$ Pesquisadora Institucional e Analista de Tecnologia de Informação da Universidade Federal de São Paulo

${ }^{4}$ Doutor em Administração pela Universidade de São Paulo (USP) e professor permanente do programa de Informática e Gestão do Conhecimento da Universidade Nove de Julho (UNINOVE)

${ }^{5}$ Doutor em Administração pela Universidade de São Paulo (USP) e professor permanente do programa de Informática e Gestão do Conhecimento da Universidade Nove de Julho (UNINOVE)
} 
ABSTRACT: This paper explore Brazilian scientific postgraduate education productions, theses and dissertations, about Information Technology Governance and Information Technology Planning from 1995 to 2014. This theme is highlighted in 2012 as a major concern of management in organizations in the world according to the 'Society for Information Management'. Using 'Plataforma Lattes' Brazilian search engine and quantitative bibliometric analysis method, this research is classified as descriptive and documentary. 263 studies were identified, with 34 theses and 229 dissertations. With 259 graduates, 104 programs in 67 different schools and 176 advisors, more than half of the works are from excellent quality programs. Most institutions and researchers, also participating in specific scientific conferences reflecting advances in the area. Nonprofit private schools, the Southeast, the state of São Paulo, the 'Universidade Católica de Brasília' and 'João Souza Neto' has been the most profitable. The theme analyzed has been the subject of research interest, notably the full growth during the period analyzed, highlighting the year 2012 and thematic category IT governance. Half of the studies have been carried out in the Business Administration, but also verified the occurrence of work areas: Production Engineering, Interdisciplinary, Computer Science and Electrical Engineering, among others, a total of ten of the 48 areas the CAPES evaluation.

Keywords: Academic Production. Information Technology Governance. Information Technology Planning. 


\section{INTRODUÇÃO}

A importância da Tecnologia da Informação (TI) enquanto propulsor do sucesso nos negócios das empresas contemporâneas tem sido cada vez mais ressaltada na literatura acadêmica. Segundo Weill e Ross (2006), organizações de excelente desempenho têm retornos sobre os investimentos em $\mathrm{Tl}$ até $40 \%$ maiores que suas concorrentes. Essas empresas de maior desempenho alcançam o valor que TI pode proporcionar por meio de uma gestão efetiva dos recursos de TI. Isso se dá pelo alinhamento entre as estratégias de negócio e o papel de TI para concretizá-las, além da mensuração e gestão dos investimentos em TI, bem como do compartilhamento e reutilização de seus ativos de TI (LUFTMAN et al., 2015). Os consideráveis investimentos de organizações não alinhados a TI quase sempre falham em atingir seus objetivos, não gerando retorno positivo sobre o capital investido em TI (KAPLAN; NORTON, 2004; LOMBARDI et al., 2016; OLUTOYIN; FLOWERDAY, 2016).

Neste sentido, a partir do maior movimento de globalização verificado nos anos 1990 em diante, a TI precisou evoluir para apoiar as organizações a auferir suas metas para alavancar vantagens competitivas e gerar maior valor para o negócio. A $\mathrm{TI}$ acabou se tornando um dos principais ativos da organização, sendo necessária ênfase na sua gestão por parte dos executivos das organizações. Tomar decisões efetivas sobre a Tl é o núcleo da governança de $\mathrm{TI}(\mathrm{GTI})$, sendo apoiado pelo planejamento estratégico de TI (PETI) (FERNANDES; ABREU, 2014; LOMBARDI et al., 2016; LUFTMAN et al., 2015; MAGALHÃES et al., 2016; WEILL; ROSS, 2006). Estudos recentes têm demonstrado que o nível de maturidade desta governança tem aumentado em empresas no Brasil (COSTA; ROSINI, 2015; GONÇALVES et al., 2016; LUNARDI et al., 2010).

Esta temática também tem sido considerada como a segunda maior preocupação de gestão nas organizações no mundo, conforme pesquisa realizada pela Society for Information Management em 2012 (LUFTMAN et al., 2013). Apesar destes assuntos terem sidos abordados em outros estudos bibliométricos (ALMEIDA; SANTOS, 2014; AVELINO et al., 2012; CHAGAS et al., 2015; FREITAS et al., 2014; GRAEML et al., 2010; MARQUES; MOTA, 2013; RASERA et al., 2010), todos focados na investigação, seja em periódicos ou congressos científicos, não foi encontrado nenhum trabalho que tenha se preocupado em realizar a análise da produção stricto sensu no país.

Apesar das teses e dissertações serem consideradas como 'literatura cinzenta', pois não foram submetidos a uma análise por pares, a mesma é considerada em alguns casos, como fonte primária disponível sobre resultados de pesquisas interdisciplinares (CÔRTES, 2006; FLICK, 2013). Nesse sentido, Ribeiro et al. (2012) consideram que este tipo de trabalho apoia o desenvolvimento, produção, socialização e progresso do conhecimento científico produzido na pós-graduação. Além disso, retratam muitas vezes o resultado dos projetos de pesquisa de determinado orientador ou grupo de pesquisa, bem como podem se tornar novos tipos de temáticas e diretrizes para periódicos ou congressos.

Diante do exposto, surge a seguinte pergunta que norteia esta pesquisa: qual é o padrão de crescimento e quais são as áreas de avaliação da CAPES que tem pesquisado acerca da temática governança e planejamento de TI nos programas stricto sensu do Brasil, no período de 1995 a 2014? Assim, o objetivo desta pesquisa é explorar a produção científica no Brasil sobre a temática governança e planejamento de $\mathrm{TI}$, a partir das dissertações e teses publicadas no país provenientes de cursos de pós-graduação stricto sensu, no período de 1995 a 2014, tendo como base de dados à plataforma CNPq Lattes. Para realizar tal análise foi efetuada uma pesquisa descritiva, documental, com a utilização 
da bibliometria, buscando-se mensurar a produção científica a partir de métodos quantitativos, a fim de se apresentar a produtividade por diferentes categorias de análise, a saber: área temática, professor orientador, instituições de ensino superior (IES), estados e regiões do país, programas, área e notas de avaliação da Coordenação de Aperfeiçoamento de Pessoal de Nível Superior (CAPES), bem como as palavras ou objetos encontrados nos títulos das dissertações e teses.

Este artigo, além da introdução, divide-se em quatro partes: fundamentação teórica, método de pesquisa, apresentação e análise dos resultados. Finaliza-se delineando uma agenda para estudos futuros.

\section{FUNDAMENTAÇÃO TEÓRICA}

\subsection{GOVERNANÇA DE TI}

As organizações de sucesso buscam relacionar suas estratégias de negócio às estratégias de $\mathrm{TI}$, promovendo assim, a adequação de suas políticas e processos por meio da seleção e implantação de aplicações de TI condizentes ao negócio (ITGI, 2011). Sistemas informatizados existentes e novas soluções podem alterar a própria empresa, bem como o relacionamento dela com outras organizações, a fim de originar ou manter competências essenciais ao sucesso do negócio (OLUTOYIN; FLOWERDAY, 2016). Neste âmbito, a GTI surge como um instrumento fundamental a fim de se tomar decisões adequadas para a correta gestão dos serviços de TI (FERNANDES; ABREU, 2014; TEODORO et al, 2014). De acordo com Weill e Ross (2006), a GTI também pode ser associada com a autoridade e responsabilidade pelas decisões referentes ao emprego, gestão e priorização dos recursos de TI. Para tanto, a alta administração deve conduzir e estabelecer os requisitos para esta governança, propiciando ainda que a TI seja também mensurada e avaliada de forma que se possa averiguar o retorno desses investimentos (LOMBARDI et al., 2016; LUFTMAN et al., 2015).

Apesar da clara distinção com outros conceitos, alguns autores apresentam outras terminologias no mesmo contexto que trata a GTI, como administração de informática ou administração de sistemas de informações (ALBERTIN; MOURA, 2009; PALMISANO; ROSINI, 2012); ou administração da informação (ADI), conforme utilizado pelo 'Encontro Nacional do ANPAD' (ENANPAD) e 'Encontro Nacional de Administração da Informação' (ENADI), congressos organizados pela Associação Nacional de Pós-graduação e Pesquisa em Administração (ANPAD), com vários trabalhos sobre esta temática de interesse (ANPAD, 2016; FREITAS et al., 2014; GRAEML et al., 2010). Outra nomenclatura é gestão estratégica da TI (VALLE, 2015), termo utilizada nos Seminários em Administração (SEMEAD), evento internacional realizado pela Faculdade de Economia, Administração e Ciências Contábeis da Universidade de São Paulo (FEA-USP), inserido na área temática intitulada 'Tecnologia da Informação' (SEMEAD, 2016). Gestão de TI (FREITAS et al., 2014) é outra possibilidade encontrada. Esta última expressão é explicitada no título do evento 'Congresso Internacional de Gestão da Tecnologia e Sistemas de Informação' (CONTECSI), outro evento promovido pela FEA-USP (CONTECSI, 2016). Mais recentemente, tem sido referenciada também como governança corporativa de TI (BERMEJO et al., 2014; ISACA, 2012).

\subsection{PLANEJAMENTO DE TI}


Segundo Kaplan e Norton (2004, p. 205), o "alinhamento estratégico é o princípio dominante na criação de valor pelos ativos intangíveis". Os gestores não questionam a imposição de alinhar os ativos intangíveis da organização. Todavia, carecem de ferramentas para articular tal alinhamento e integração. As técnicas de alinhamento da Tl oferecem uma abordagem funcional para alinhar os ativos do capital da informação aos objetivos estratégicos da organização (FERNANDES; ABREU, 2014; TEODORO et al, 2014).

Uma das ferramentas para se realizar este alinhamento é a elaboração do planejamento estratégico de TI (PETI), como parte derivada do planejamento estratégico organizacional, tanto para organizações privadas, quanto para organizações públicas (BERMEJO et al., 2014; MAGALHÃES et al., 2016). Ambos devem ter estratégias alinhadas, exercendo uma função estratégica de adição de valor aos produtos e serviços da organização. Cabe uma breve distinção: o planejamento estratégico organizacional é amplo e genérico, contemplando objetivos e estratégias corporativos que são direcionadores para cada uma das áreas organizacionais: administrativa, financeira, recursos humanos, comercial, assim como a TI (ALBERTIN; MOURA, 2009; FERNANDES; ABREU, 2014). A elaboração e implantação do PETI, por sua vez, deverá auxiliar a empresa no cumprimento dos objetivos e das estratégias traçadas, a partir do desenho e correta implantação de sistemas de informação (operacionais, gerenciais e estratégicos) e de outros recursos (hardware, software, sistemas de telecomunicações e gestão de dados e informações). Ao mesmo tempo, o PETI contribuirá também, com as habilidades e competências humanas necessárias para a gestão da estratégia (LUFTMAN et al., 2015; LUNARDI et al., 2010; OLUTOYIN; FLOWERDAY, 2016).

\subsection{FRAMEWORKS DE GOVERNANÇA E PLANEJAMENTO DE TI}

Seja um projeto de implantação do PETI ou de melhoria da governança de TI, estes devem ser elaborados por meio de uma metodologia ou em conjunto com algum framework, sendo que os mais relevantes são: COBIT e ITIL, dentre outros. Também chamados de modelos, tem como objetivo maximizar o valor da $\mathrm{Tl}$ e gerar maior alinhamento com as estratégias do negócio (ALI et al., 2013; OLUTOYIN; FLOWERDAY, 2016; SELIG, 2016).

O COBIT tem como objetivos: criar valor para a organização e seus stakeholders, permitir que a área de TI seja gerenciada de forma holística, manter a estabilidade entre a realização de benefícios, a melhoria dos níveis de risco e a otimização do uso dos recursos de TI (GONÇALVES et al., 2016; ISACA, 2012). Enquanto o COBIT tem se firmado como principal modelo para a governança de TI, o ITIL se tornou o conjunto de melhores práticas de padrão mundial para o gerenciamento de serviços de $\mathrm{Tl}$, oferecendo maior valor à organização e maior satisfação aos usuários. O ITIL volta-se tanto à estratégia de serviços, projeto de serviços, transição de serviços, operação de serviços, quanto à busca pela melhoria contínua de serviços de TI (FERNANDES; ABREU, 2014).

Ali et al. (2013) comentam que tem havido grande expansão no uso desses modelos. Porém, o uso isolado apenas de uma dessas ferramentas não garante o sucesso da TI na organização, pois tais instrumentos oferecem fundamentos, estruturas e práticas que devem ser ambientados à maturidade e à cultura organizacional, considerando-se também a capacidade dos recursos, sejam eles tecnológicos, financeiros ou humanos (TEODORO et al, 2014; WOLMARANS et al., 2016). 


\subsection{PRODUÇÃO CIENTÍFICA SOBRE GOVERNANÇA E PLANEJAMENTO DE TI}

Durante a elaboração da revisão da literatura, foi possível identificar sete trabalhos nacionais bibliométricos realizados nos últimos anos seis anos, especificamente sobre os temas governança e planejamento de $\mathrm{Tl}$, tanto em periódicos e anais de congressos da área de administração, como da ciência da informação. Respectivamente, é apresentado em ordem cronológica: Graeml et al. (2010); Rasera et al. (2010); Avelino et al. (2012); Marques; Mota (2013); Almeida; Santos (2014); Freitas et al. (2014) e Chagas et al. (2015).

Lunardi et al. (2010) apresentam uma proposta de classificação sobre a temática governança de TI agrupando-a em seis áreas centrais: alinhamento estratégico, entrega de valor, gerenciamento de risco, gerenciamento de recursos, mensuração de performance e accountability. Destas seis áreas da GTI, segundo Rasera et al. (2010) e Marques e Mota (2013), a área mais referenciada é o 'alinhamento estratégico da TI ao negócio'. Estes últimos autores também averiguaram que os modelos de GTI estão em grande evidência nos trabalhos mais recentes das pesquisas da academia. Já no trabalho conduzido por Almeida e Santos (2014), consideraram apenas uma única área intitulada 'alinhamento estratégico da $\mathrm{Tl}^{\prime}$ como objeto da pesquisa. Estes encontraram o maior número de trabalhos nesta temática no CONTECSI em comparação aos demais eventos da ANPAD (ENANPAD e ENADI), além da prevalência da abordagem qualitativa e uso do estudo de caso em seus artigos analisados.

Pesquisa conduzida por Chagas et al. (2015) consideraram apenas a temática governança de TI. Estes autores focaram exclusivamente sobre GTI na administração pública, tendo verificado incipiência no desenvolvimento desta temática. Já nas pesquisas bibliométricas de Avelino et al. (2012); Freitas et al. (2014) e Graeml et al. (2010), apesar de não terem o foco exclusivo em GTI, também tiveram destaque por estarem relacionadas a esta temática. Avelino et al. (2012) tinham como objetivo analisar a produção no CONTECSI no período de 2005 a 2011, tendo verificado que a temática GTI é a mais comum neste congresso em específico, com $27 \%$ do total de trabalhos, considerando de forma similar o termo gestão de sistemas de informação. Graeml et al. (2010) fizeram a análise das redes sociais da área de ADI da ANPAD, enquanto Freitas et al. (2014) constataram que 37\% dos trabalhos desta mesma área referem-se à temática GTI.

Assim, foi considerada como tema central e foco desta pesquisa, a área de GTI voltada ao alinhamento estratégico de TI e seus principais frameworks de apoio, uma vez que esta engloba a temática central governança e planejamento de TI como um todo.

\section{MÉTODO DE PESQUISA}

Para se atingir o objetivo deste trabalho foi realizada uma pesquisa descritiva documental com a utilização da bibliometria. A bibliometria é uma técnica de pesquisa para apoio na análise e avaliação da produção intelectual científica de uma determinada área, considerando-se um período prolongado de tempo, com um número significativo de amostras, a partir do emprego de métodos quantitativos (CHUEKE; AMATUCCI, 2015; FLICK, 2013; RIBEIRO et al., 2012).

A Plataforma Lattes foi escolhida em detrimento a outras bases para levantamento de teses e dissertações, por estar consolidada como principal base de dados de referência para obtenção de informações sobre a trajetória acadêmica de pesquisadores brasileiros (AUTRAN et al., 2015; MORAES; OLIVEIRA, 2010). 
Assim, foi realizada uma exaustiva busca manual na Plataforma Lattes (CNPQ, 2015) por meio do mecanismo de busca simples, por assunto, apenas a base de doutores, no período de junho de 2015 a janeiro de 2016, levantando trabalhos relacionados aos temas voltados ao objetivo desta pesquisa a partir dos seguintes dados individuais: 1) Dissertações de mestrado e/ou teses de doutorado defendidas pelo próprio pesquisador ou 2) Participação em bancas de trabalhos de conclusão e/ou orientações e supervisões concluídas de dissertação de mestrado e teses de doutorado.

Foram definidas algumas das principais palavras-chave que aparecem na literatura, conforme referenciado na fundamentação teórica já exposta, e que são apresentadas no Quadro 1. Cada palavra-chave foi agrupada em uma das três categorias temáticas: 1) Governança de $\mathrm{Tl}$; 2) Planejamento de $\mathrm{Tl}$ e 3) Frameworks de governança e planejamento de $\mathrm{TI}$, doravante denominado apenas como frameworks de TI. A coleta foi realizada apenas quando o 'título da obra' (dissertação ou tese) se enquadrava em uma ou mais palavraschave disponíveis no Quadro 1, podendo a obra então ser catalogada em mais de uma categoria de análise. Outras palavras-chave foram utilizadas para a realização da pesquisa, porém, não retornaram nenhum resultado, sendo posteriormente omitidas do quadro a seguir.

\begin{tabular}{l|l}
\hline Categoria temática & \multicolumn{1}{|c}{ Palavras-chave relacionadas durante a realização da coleta de dados } \\
\hline Governança de TI & $\begin{array}{l}\text { Administração da tecnologia, administração da TI, administração de tecnologia, } \\
\text { estratégia da tecnologia, estratégia de sistemas, estratégia de TI, gerenciamento da } \\
\text { tecnologia, gerenciamento de tecnologia, gerenciamento de ti, gestão da informática, } \\
\text { gestão da tecnologia, gestão da TI, gestão de informática, gestão de tecnologia, gestão } \\
\text { de TI, gestão estratégica da tecnologia, gestão estratégica de sistemas, governança } \\
\text { corporativa de TI, governança da tecnologia, governança de sistemas, governança de } \\
\text { tecnologia, governança de TI, governança em TI }\end{array}$ \\
\hline Planejamento de TI & $\begin{array}{l}\text { Alinhamento da estratégia, alinhamento da ti, alinhamento estratégico, PDTI, PETI, } \\
\text { planejamento da tecnologia, planejamento de tecnologia, planejamento estratégico da } \\
\text { tecnologia, planejamento estratégico de SI, planejamento estratégico de sistemas, } \\
\text { planejamento estratégico de tecnologia, planejamento estratégico de TI, planejamento } \\
\text { estratégico para tecnologia, plano diretor de informática, plano diretor de tecnologia }\end{array}$ \\
\hline Frameworks de TI & $\begin{array}{l}\text { coBIT, frameworks de governança, ITIL, mecanismos de governança, modelos de } \\
\text { governança }\end{array}$ \\
\hline
\end{tabular}

Quadro 1 - Palavras-chave relacionadas às categorias temáticas de análise Fonte: Autores da pesquisa

Ao final da realização da coleta, as entradas selecionadas foram agrupadas em um banco de dados em formato MS-Excel e MS-Access, sendo realizada sua consolidação com a consequente eliminação de possíveis duplicações das ocorrências encontradas, retornandose consulta à Plataforma Lattes para dirimir dúvidas, quando necessário. Para a conferência e unificação das terminologias em relação às instituições de origem, situação dos programas, área de avaliação e notas atribuídas pela CAPES (avaliação trienal 2013, referente ao triênio 2010-2012), foi realizada consulta à Plataforma Sucupira (CAPES, 2015). Em relação à informação sobre categoria administrativa das instituições de origem, foi realizada consulta à Plataforma E-MEC (MEC, 2016). As dissertações e teses nitidamente fora da temática proposta para este trabalho também foram desconsideradas, como também aqueles trabalhos cadastrados no Lattes que tenham sido realizados integralmente fora do Brasil. 
Com isso, a análise bibliométrica procedida nesta pesquisa foi feita mediante os seguintes indicadores: 1) Produção por níveis e categorias temáticas; 2) Orientadores com maior produção; 3) Instituições de Ensino Superior (IES) com maior produção, em conjunto com a respectiva categoria administrativa, região do país e estado da federação; 4) Programas com maior produção e por instituição; 5) Produção por áreas de avaliação da CAPES e, por fim; 6) Frequência das palavras ou objetos encontrados nos títulos.

\section{APRESENTAÇÃO E ANÁLISE DOS RESULTADOS}

\subsection{PRODUÇÃO POR NÍVEIS E CATEGORIAS TEMÁTICAS}

Na llustração 1 é apresentado o total de trabalhos encontrados em cada um dos três níveis avaliados, agrupados em Doutorado (DO) e, para o nível de Mestrado, segregado em Mestrado Acadêmico (ME) e Mestrado Profissional (MP).

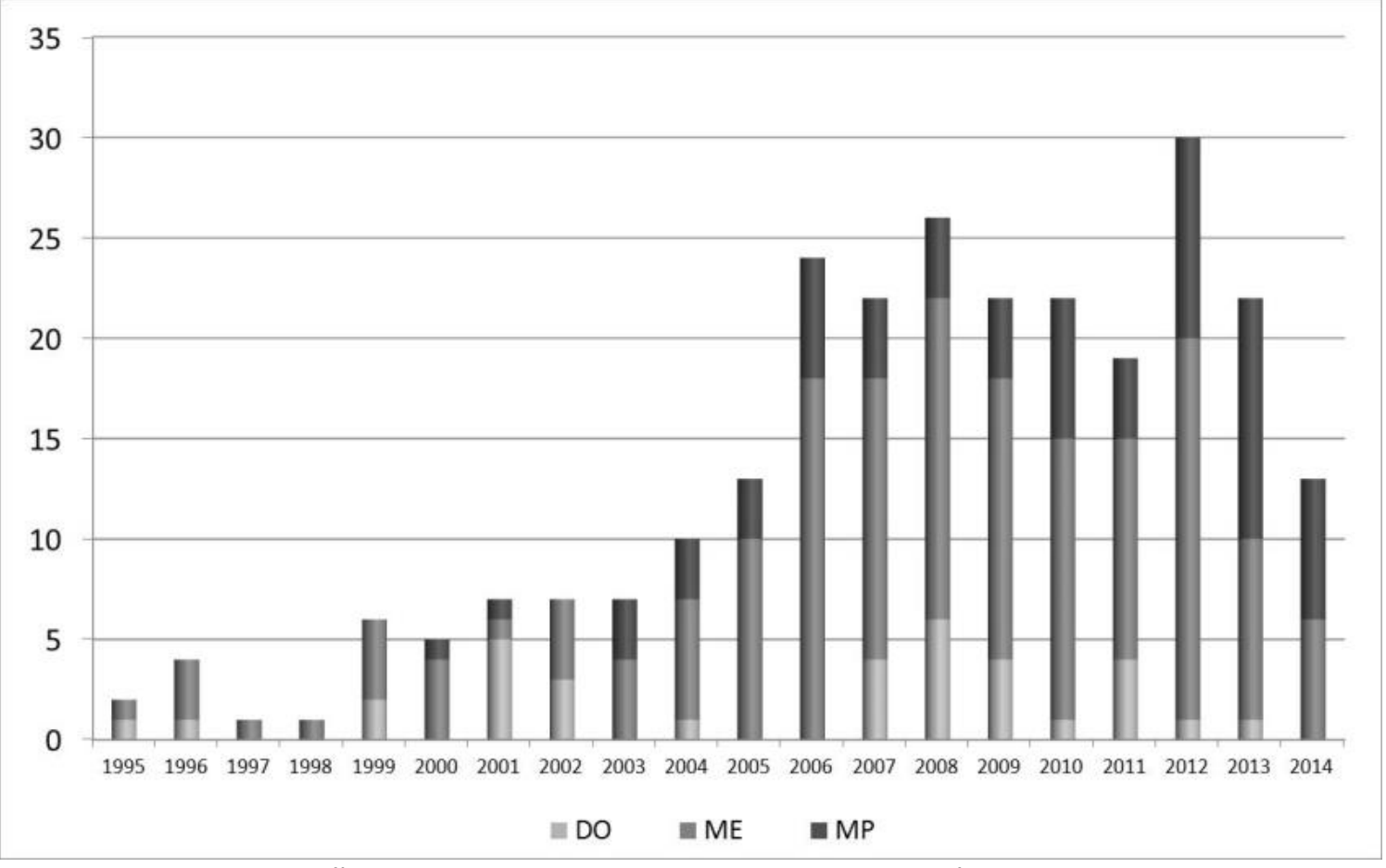

Ilustração 1 - Total de trabalhos encontrados por nível, ano a ano

Fonte: Autores da pesquisa.

Foram encontrados 263 trabalhos, sendo 34 teses, 160 dissertações acadêmicas e 69 dissertações de mestrado profissional na série histórica analisada, compreendida pelo período entre 1995 e 2014.

As teses foram concluídas em maior quantidade os anos de 2008 e 2001, com seis e cinco trabalhos (32\% das teses) respectivamente. Quando considerado apenas o mestrado profissional (MP), introduzido no país a partir de 1999, o ano de 2013 teve maior destaque em conjunto com 2012, com 12 e 10 trabalhos (32\% das dissertações profissionais), respectivamente. Já em relação ao mestrado acadêmico (ME), com 19 e 18 trabalhos (17\% das dissertações acadêmicas), respectivamente, os anos de 2012 e 2006 obtiveram a maior quantidade de dissertações defendidas.

Afere-se que os anos de 2012 (30 trabalhos), 2008 (26) e 2006 (24) foram os mais produtivos, com $30 \%$ do total dos trabalhos da temática prospectada no período analisado. 
Além disso, verificou-se que apenas a partir do ano de 2004 houve produção superior a dez trabalhos no mesmo ano, ou seja, praticamente na metade final dos anos da série histórica pesquisada. Outra análise possível é que, após o pico verificado em 2012, percebe-se uma tendência de queda, considerando os dois e últimos anos coletados (2013 e 2014).

Graeml et al. (2010) já constatavam que essa temática (GTI) desenvolvida numa rede de cocitação da área de ADI da ANPAD estava sendo ampliada a partir do ano de 2002, diferentemente do que acontecia em anos anteriores, em que a temática que se destacava era ainda a informatização. Freitas et al. (2014) também já classificava o período até 2002 como período de alavancagem da grande área $A D I$ e o período seguinte como período de consolidação, o que realmente pode ser observado a partir da tendência de crescimento a partir do referido ano. Percebe-se grande distinção em relação aos períodos apontados quando comparados com os trabalhos de Almeida e Santos (2014), Chagas et al. (2015) e Marques e Mota (2013), uma vez que o destaque para estes trabalhos foi para o ano de 2011.

Além disso, foi identificado que apenas quatro, dos 259 alunos egressos identificados optaram, para desenvolvimento de ambos os trabalhos (mestrado e doutorado), pela continuidade da temática de pesquisa, uma vez que ambos os títulos eram relacionados entre si. Os quatro autores identificados foram: Andréa de Paiva Gonçalves, Celso Pires Machado, Jorge Luís Cordenonsi e Mauro Borges da Silva. Outra indicação importante é que três orientadores (Ângela Freitag Brodbeck, Antônio Roberto Ramos Nogueira e Jorge Luís Nicolas Audy) são alunos egressos de doutorado que apresentaram títulos de suas teses consonantes à temática analisada no período verificado.

Na llustração 2 é apresentado o total de trabalhos encontrados em cada uma das três categorias temáticas analisadas, a partir da coleta realizada.

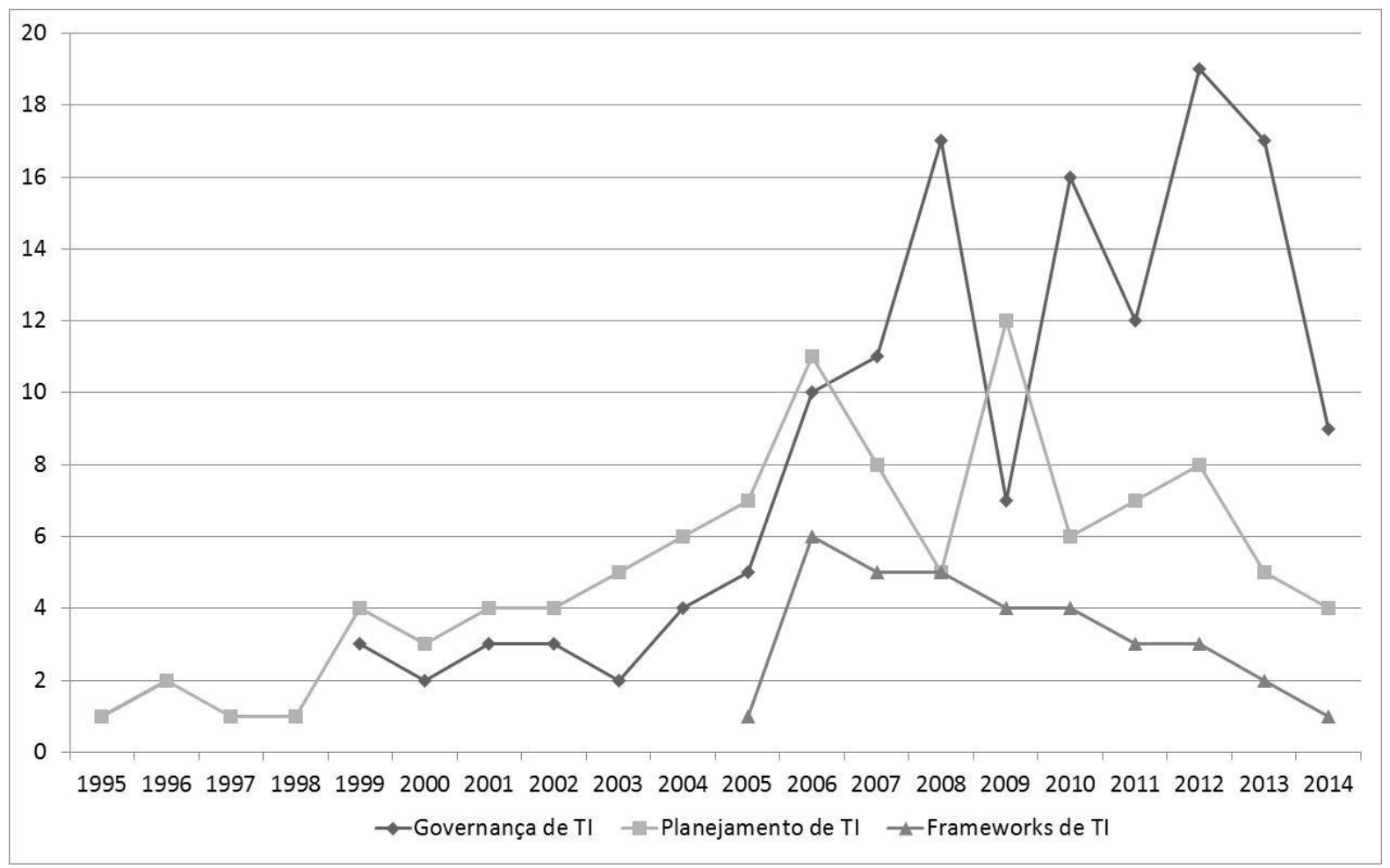

Ilustração 2 - Total de trabalhos encontrados por categoria temática, ano a ano Fonte: Autores da pesquisa 
Em relação à categoria temática 'governança de $\mathrm{Tl}^{\prime}$, esta teve maior destaque quando comparada à categoria 'planejamento de $\mathrm{Tl}^{\prime}$, com 143 trabalhos (54\% do total) e 104 trabalhos ( $40 \%$ do total), respectivamente. Porém, é interessante ressaltar que, quando verificadas apenas as teses de doutorado, o maior destaque volta-se para a categoria 'planejamento de $\mathrm{Tl}^{\prime}$ ', com 19 trabalhos, enquanto a categoria 'governança de $\mathrm{Tl}^{\prime}$ apresentou 14 trabalhos.

Outra constatação é que a escolha do assunto principal nos trabalhos de pósgraduação stricto sensu, na categoria temática 'frameworks de $\mathrm{Tl}^{\prime}$, foi realizada apenas na segunda metade da série histórica, mais precisamente a partir do ano 2005. Além disso, observa-se que esta categoria temática teve a menor quantidade de trabalhos no total, apenas 34 , ou $13 \%$ do total, e também a menor quantidade de teses, com apenas dois trabalhos concluídos.

Ademais, percebe-se início dos trabalhos em 2005 e posteriormente uma diminuição do interesse na categoria temática 'frameworks de $\mathrm{Tl}^{\prime}$, diferente do que se verifica nas outras duas categorias temáticas analisadas ('planejamento de $\mathrm{Tl}^{\prime}$ e 'governança de $\mathrm{TI}^{\prime}$ ), que se encontram em tendência de crescimento, considerando-se a série histórica analisada como um todo. Marques e Mota (2013) já observavam também o menor interesse quando considerada essa categoria temática ('frameworks de $\mathrm{Tl}^{\prime}$ ) em detrimento as outras duas, 'governança de $\mathrm{Tl}^{\prime}$ e 'planejamento de $\mathrm{Tl}^{\prime}$.

\subsection{ORIENTADORES COM MAIOR PRODUÇÃO}

Na Tabela 1 são apresentados os quatro orientadores mais profícuos, com pelo menos quatro trabalhos, bem como nome da instituição onde foi realizada a orientação. Foi agrupado também qual foi o nível de orientação realizado em cada uma das três categorias temáticas prospectadas, tendo sido alcançados 176 orientadores no total.

\begin{tabular}{l|l|r|r}
\hline \multicolumn{1}{c|}{ Nome do Orientador } & \multicolumn{1}{|c|}{ Instituição } & Nível * & Total \\
\hline João Souza Neto & Universidade Católica de Brasília & ME, MP & $\mathbf{1 0}$ \\
\hline Adolfo Alberto Vanti & Universidade do Vale do Rio dos Sinos & ME & $\mathbf{8}$ \\
\hline Ângela Freitag Brodbeck & Universidade Federal do Rio Grande do Sul & DO, ME & $\mathbf{6}$ \\
\hline Napoleão Verardi Galegale & Centro Estadual de Educação Tecnológica Paula Souza & MP & $\mathbf{6}$ \\
\hline 43 orientadores com 2 a 4 trabalhos & & 104 \\
\hline 129 orientadores com um trabalho & & $\mathbf{1 2 9}$ \\
\hline Total & & $\mathbf{2 6 3}$ \\
\hline
\end{tabular}

Tabela 1 - Orientadores com maior produção, por categoria temática

Fonte: Autores da pesquisa

Notas: * DO - doutorado, ME - mestrado acadêmico, MP - mestrado profissional

Verifica-se que João Souza Neto, da Universidade Católica de Brasília, além de ser o docente com maior número de orientações realizadas (10), destaca-se também com a maior quantidade de orientações (8) de Mestrado Profissional. Além disso, também emerge como orientador com maior quantidade de trabalhos nas categorias temáticas 'planejamento de $\mathrm{TI}^{\prime}$ (6) e 'frameworks de $\mathrm{Tl}^{\prime}$ (3). Tais orientações foram realizadas em cursos das áreas de conhecimento CAPES 'Interdisciplinar' e 'Engenharias IV'.

Em seguida, o docente com maior quantidade de orientações é Adolfo Alberto Vanti, da Universidade do Vale do Rio dos Sinos, com oito trabalhos, todos de mestrado acadêmico, sendo também o orientador mais proficiente neste nível em específico. Todos os 
trabalhos orientados por ele foram em cursos da área de conhecimento CAPES 'Administração, Ciências Contábeis e Turismo'.

Com maior quantidade de trabalhos na categoria temática 'planejamento de $\mathrm{Tl}^{\prime}$ (6), Ângela Freitag Brodbeck, da Universidade Federal do Rio Grande do Sul também merece destaque. Ela também é a orientadora com maior quantidade de trabalhos de doutorado concluídos (3).

Outro destaque é Napoleão Verardi Galegale do Centro Estadual de Educação Tecnológica Paula Souza, com seis trabalhos orientados no total, todos oriundos de curso vinculado à área de conhecimento CAPES 'Engenharias III' .

Além disso, foi constatado que a maioria dos orientadores (129 dos 176 orientadores encontrados), tem apenas um trabalho orientado na temática pesquisada. Em suma, apenas $27 \%$ dos orientadores têm mais de um trabalho orientado na temática analisada nesta pesquisa.

Coadunando com os dez autores mais proficientes da temática GTI identificados por Freitas et al. (2014), oito deles também são observados na amostra deste trabalho. Foi constatado ainda que $54 \%$ dos artigos analisados por Almeida e Santos (2014) têm pelo menos um aluno egresso ou orientador, resultados que também foram encontrados nesta pesquisa. Quando comparados com Marques e Mota (2013), os resultados indicam que sete dos oito autores com maior produção também foram detectados nos dados coletados para esta pesquisa. Isso reflete a participação destes pesquisadores também em congressos científicos específicos de temática na área, uma vez que foram encontrados sete pesquisadores na atual coleta, quando comparados os resultados aos onze pesquisadores mais profícuos indicados por Rasera et al. (2010).

\subsection{INSTITUIÇÕES DE ENSINO SUPERIOR (IES) COM MAIOR PRODUÇÃO}

A Tabela 2 apresenta as quatro IES com maior volume de publicações (mais de dez trabalhos) de um total de 67 IES identificadas, incluindo-se a esfera pública e privada e a respectiva unidade da federação na qual atua.

\begin{tabular}{l|l|r|r}
\hline IES atual & Categoria administrativa & UF & Total \\
\hline Universidade Católica de Brasília & Particular sem fins lucrativos & DF & 22 \\
\hline Universidade Federal de Pernambuco & Pública federal & PB & 18 \\
\hline Universidade Federal do Rio Grande do Sul & Pública federal & RS & 15 \\
\hline Universidade de São Paulo & Pública estadual & SP & 14 \\
\hline 11 instituições com seis a dez trabalhos & --- & --- & 92 \\
\hline 25 instituições com dois a cinco trabalhos & --- & --- & 75 \\
\hline 27 instituições com um trabalho & --- & --- & 27 \\
\hline Total & & & $\mathbf{2 6 3}$ \\
\hline
\end{tabular}

Tabela 2 - Total de trabalhos por IES, categoria administrativa e unidade federativa Fonte: Autores da pesquisa

Quando analisado o total de trabalhos por IES a partir de sua categoria administrativa, destaca-se uma instituição particular com maior número de trabalhos: Universidade Católica de Brasília, sendo 22 no total (8\% do total). Duas IES públicas federais constam também nessa relação: Universidade Federal de Pernambuco e Universidade Federal do Rio Grande do Sul, com 18 e 15 trabalhos, respectivamente. Quando comparado com Rasera et al. (2010) e Freitas et al. (2014), a instituição destacada com maior produção, 
laços e centralidade em sua rede de cooperação, referente a eventos do ANPAD, foi a Universidade Federal do Rio Grande do Sul, terceira mais profícua verificada neste estudo. A Universidade de São Paulo é a única pública estadual que se destaca nessa relação, com catorze trabalhos no total. Avelino et al. (2012) já identificavam essa instituição como a mais profícua em seu trabalho bibliométrico sobre o CONTECSI. Dos dezenove autores mais profícuos deste trabalho, seis (32\%) apresentaram-se na amostra analisada nesta pesquisa.

Defrontando-se em relação às dez instituições mais profícuas identificadas por Freitas et al. (2014), oito delas também se encontram no ranking entre as dez com maior número de trabalhos da atual amostra pesquisada. Ao se deparar com Rasera et al. (2010), todas as instituições identificadas foram também encontradas nesta pesquisa.

Na tabela 3 é apresentada a produtividade por estado da federação.

\begin{tabular}{|c|c|c|c|c|}
\hline Estado da federação & DO & ME & MP & Total \\
\hline SP & 14 & 38 & 18 & 70 \\
\hline RS & 8 & 29 & 0 & 37 \\
\hline RJ & 3 & 20 & 11 & 34 \\
\hline 3 estados com 18 a 26 trabalhos (DF, MG e PE) & 4 & 28 & 32 & 64 \\
\hline 3 estados com 12 a 14 trabalhos (SC, BA e PR) & 5 & 29 & 5 & 39 \\
\hline 3 estados com dois a seis trabalhos (CE, ES e RN) & 0 & 11 & 2 & 13 \\
\hline 6 estados com um trabalho (AC, AL, AM, PB, RO e SE) & 0 & 5 & 1 & 6 \\
\hline 9 estados com nenhum trabalho (AP, GO, MA, MS, MT, PA, PI, RR, TO) & 0 & 0 & 0 & 0 \\
\hline Total & 34 & 160 & 69 & 263 \\
\hline
\end{tabular}

Tabela 3 - Total de trabalhos por estado da federação

Fonte: Autores da pesquisa

Ao se verificar a produção por estado da federação, percebe-se que o estado de São Paulo está na primeira colocação, com 70 trabalhos ( $27 \%$ do total), seguido dos estados do Rio Grande do Sul (37), Rio de Janeiro (34), Distrito Federal (26), Minas Gerais (20) e Pernambuco (18). Há de se ressaltar também a condição de nove estados da federação, que não apresentaram nenhum trabalho defendido na temática analisada, quais sejam: Amapá, Goiás, Maranhão, Mato Grosso, Mato Grosso do Sul, Pará, Piauí, Roraima e Tocantins. Os demais estados têm pelo menos um único trabalho concluído. Quando verificadas as regiões geográficas do país, o Sudeste tem quase a metade dos trabalhos concluídos, com 129 (49\% do total), inclusive com maior número de teses e dissertações, quando analisadas separadamente. Em seguida, foram encontradas defesas de programas de pós-graduação no Sul (63), Nordeste (42), Centro-oeste (26) e Norte (3).

$\mathrm{Na}$ llustração 3 é apresentado o total de trabalhos, por categoria administrativa (pública e particular). 


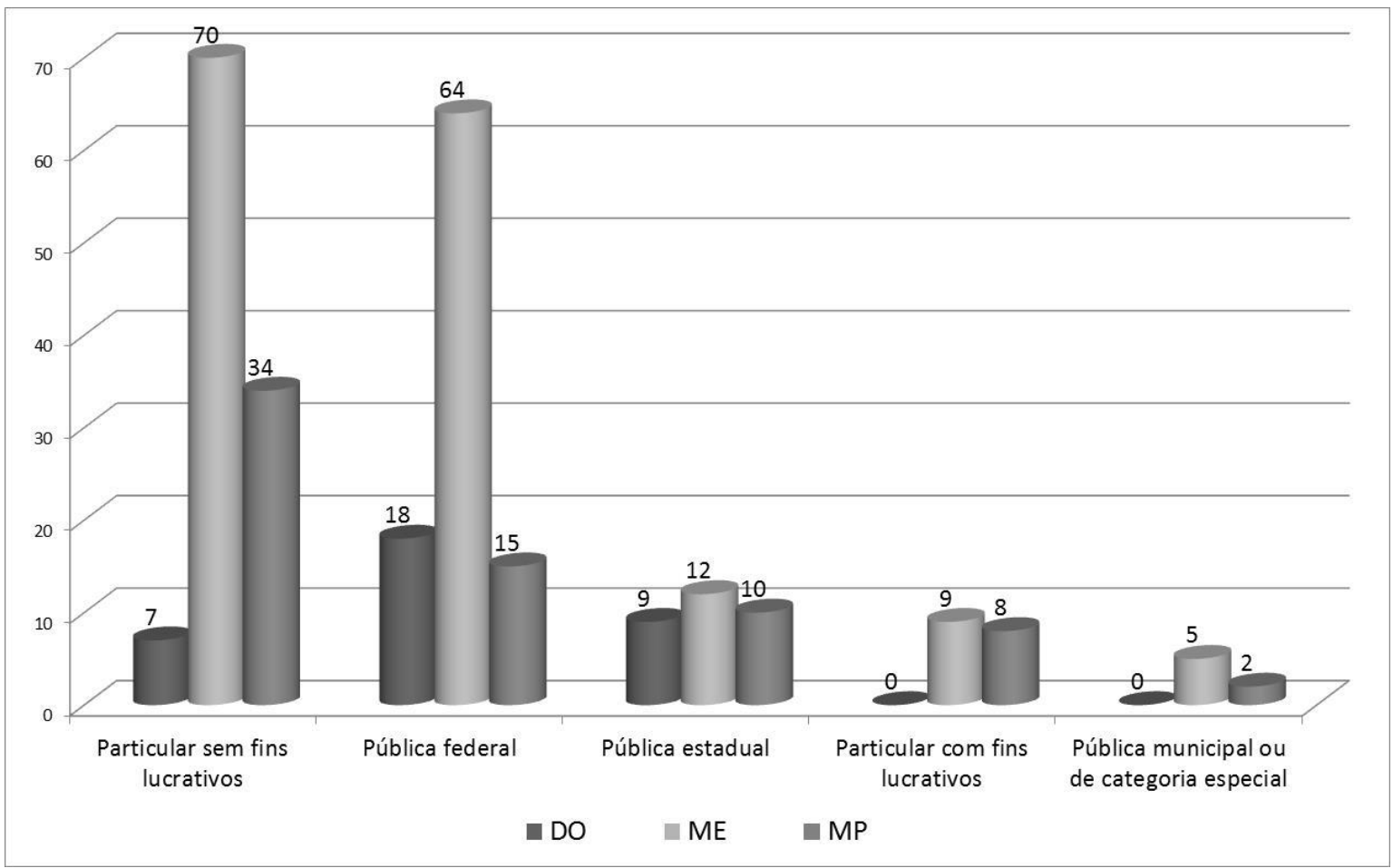

Ilustração 3 - Total de trabalhos por categoria administrativa

Fonte: Autores da pesquisa

A respeito da categoria administrativa, 111 trabalhos foram concluídos em instituições particulares sem fins lucrativos ( $42 \%$ do total), seguido de públicas federais (97), públicas estaduais (31), particulares com fins lucrativos (17) e por último, públicas municipais ou de categoria especial (7). As teses têm maior prevalência nas instituições públicas federais (7), enquanto as dissertações foram encontradas em maior quantidade nas instituições particulares sem fins lucrativos (104).

\subsection{PROGRAMAS COM MAIOR PRODUÇÃO}

$\mathrm{Na}$ Tabela 4 são apresentados os cinco programas stricto sensu e respectiva IES com maior quantidade de trabalhos, a partir dos dados coletados na pesquisa. É apresentada também a respectiva nota da avaliação de 2013 atribuída pela CAPES ao curso. 


\begin{tabular}{|c|c|c|c|c|c|c|}
\hline Nome do programa & IES atual & Nota CAPES & DO & ME & MP & Total \\
\hline $\begin{array}{l}\text { Gestão do Conhecimento e da } \\
\text { Tecnologia da Informação }\end{array}$ & \begin{tabular}{|l|} 
Universidade Católica de \\
Brasília \\
\end{tabular} & $4(\mathrm{MP})$ & 0 & 0 & 20 & 20 \\
\hline Administração & $\begin{array}{l}\text { Universidade Federal do Rio } \\
\text { Grande do Sul } \\
\end{array}$ & 5 (D), 5 (ME) & 7 & 5 & 0 & 12 \\
\hline Administração de Empresas & Fundação Getúlio Vargas/SP & 7 (D), 7 (ME) & 4 & 6 & 0 & 10 \\
\hline Administração e Negócios & \begin{tabular}{|l|} 
Pontifícia Universidade \\
Católica do Rio Grande do Sul \\
\end{tabular} & $5(\mathrm{ME})$ & 0 & 9 & 0 & 9 \\
\hline Ciências da Computação & $\begin{array}{l}\text { Universidade Federal de } \\
\text { Pernambuco }\end{array}$ & 6 (D), 6 (ME), 3 (MP) & 1 & 7 & 1 & 9 \\
\hline 9 programas com 5 a 8 trabalhos & $-\cdots$ & --- & 6 & 30 & 18 & 54 \\
\hline 34 programas com 2 a 4 trabalhos & --- & --- & 11 & 60 & 22 & 93 \\
\hline 56 programas com 1 trabalho & --- & --- & 5 & 43 & 8 & 56 \\
\hline Total & & & 34 & 160 & 69 & 263 \\
\hline
\end{tabular}

Tabela 4 - Total de trabalhos por programas incluindo IES e nota da CAPES

Fonte: Autores da pesquisa

Dos programas com maior produtividade, destacam-se: Gestão do Conhecimento e da Tecnologia da Informação, curso da área de conhecimento Interdisciplinar da Universidade Católica de Brasília, com 20 trabalhos (7\% do total), sendo oferecido apenas no nível Mestrado Profissional. Este programa foi avaliado pela CAPES em 2013 com nota 'Quatro'.

Na sequência, constam três programas da área da Administração, das seguintes instituições: Universidade Federal do Rio Grande do Sul (12), Fundação Getúlio Vargas/SP (10) e Pontifícia Universidade Católica do Rio Grande do Sul (9). Com exceção à Fundação Getúlio Vargas/SP, que tem nota 'Sete' em seu programa, as demais obtiveram nota 'Cinco' na avaliação CAPES em 2013.

Em quinta colocação aparece um único programa da área Ciência da Computação, oferecido pela Universidade Federal de Pernambuco, com o total de nove trabalhos. Sua classificação é nota 'Seis' para os cursos de doutorado e mestrado acadêmico, e nota três para o curso de mestrado profissional, conforme avaliação feita pela CAPES em 2013.

Assim, verifica-se dentre os cinco programas com maior quantidade de trabalhos, também a alta qualidade associada aos seus cursos, considerando-se a nota da avaliação de 2013 da CAPES. Além disso, no total geral foram identificados trabalhos oriundos de 20 cursos de doutorado, 81 cursos de mestrado acadêmico e 21 cursos de mestrado profissional. Desconsiderando-se o nível, foram encontrados 104 cursos distintos de 67 diferentes IES.

Na llustração 4 é apresentado o total de trabalhos, a partir das notas de avaliação da CAPES para os respectivos cursos. 


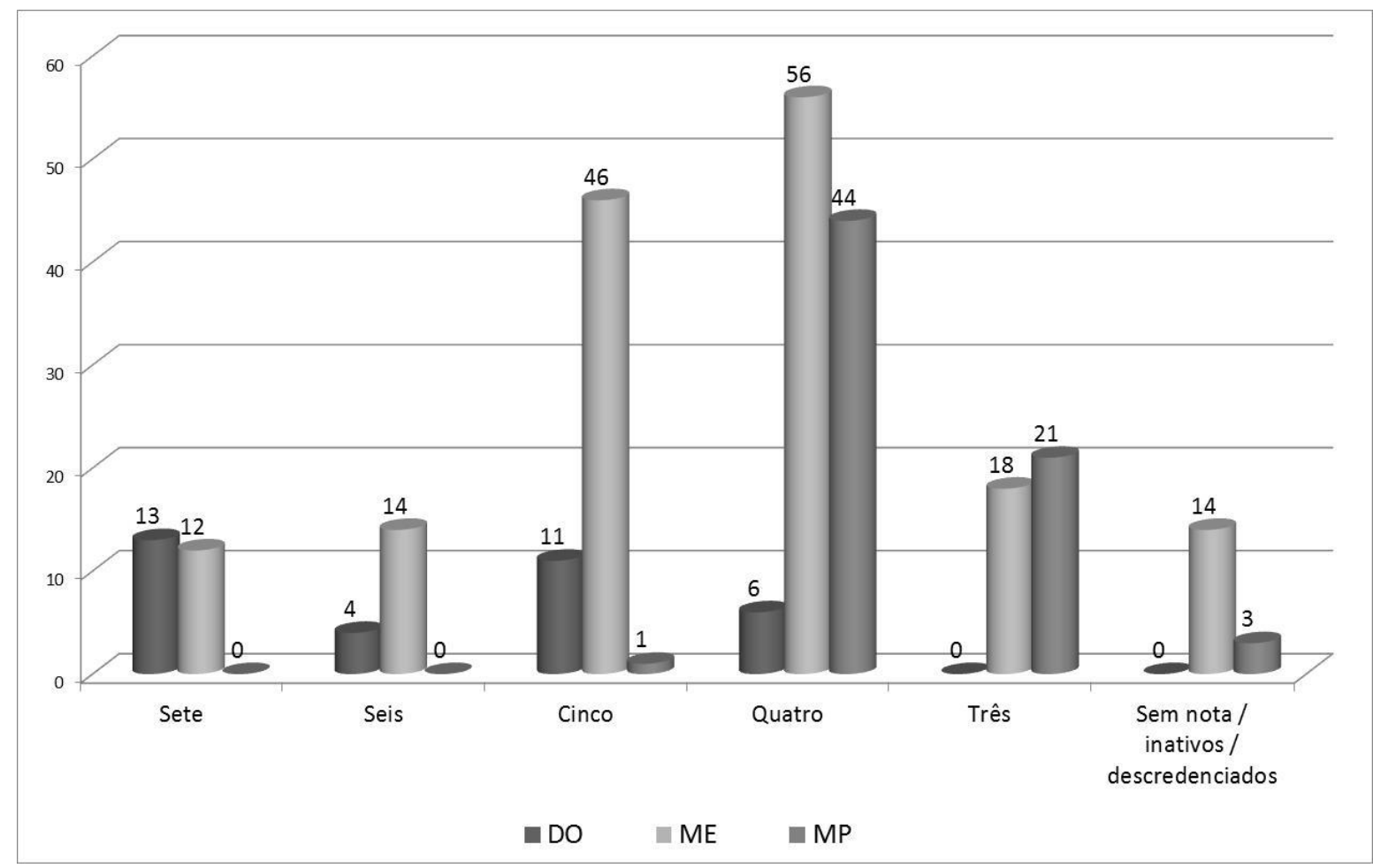

Ilustração 4 - Total de trabalhos por notas de avaliação CAPES e níveis de curso *

Fonte: Autores da pesquisa

Nota: * Nota da avaliação da CAPES de 2013, referente a cada curso analisado

A maior quantidade de trabalhos, quando considerada as notas da avaliação CAPES de 2013 dos respectivos cursos, é a nota 'Quatro', com o total de 106 trabalhos (40\% do total), seguido das notas 'Cinco' (58), 'Três' (39), 'Sete' (25) e 'Seis' (18).

Ao analisar apenas as teses de doutorado, a maior quantidade (13) é oriunda de cursos nota 'Sete', conferindo excelência internacional aos trabalhos realizados nestes programas (38\% das teses). Para os trabalhos de mestrado acadêmico (56) e profissional (44), a nota 'Quatro' foi a que mais predominou nos cursos analisados.

Além disso, mais da metade das teses e dissertações acadêmicas encontradas (100 de 194 trabalhos) são oriundas de programas de qualidade excelente, com no mínimo nota 'Cinco' na avaliação da CAPES de 2013. Não foram considerados os trabalhos oriundos de cursos de mestrado profissional, uma vez que tais cursos têm critérios diferenciados de avaliação.

\subsection{PRODUÇÃO POR ÁREA DE AVALIAÇÃO DA CAPES}

$\mathrm{Na}$ Ilustração 5 é apresentado o total de trabalhos agrupadas nas cinco áreas de conhecimento com maior produção, conforme classificação da CAPES de 2013 para fins de avaliação dos programas. 


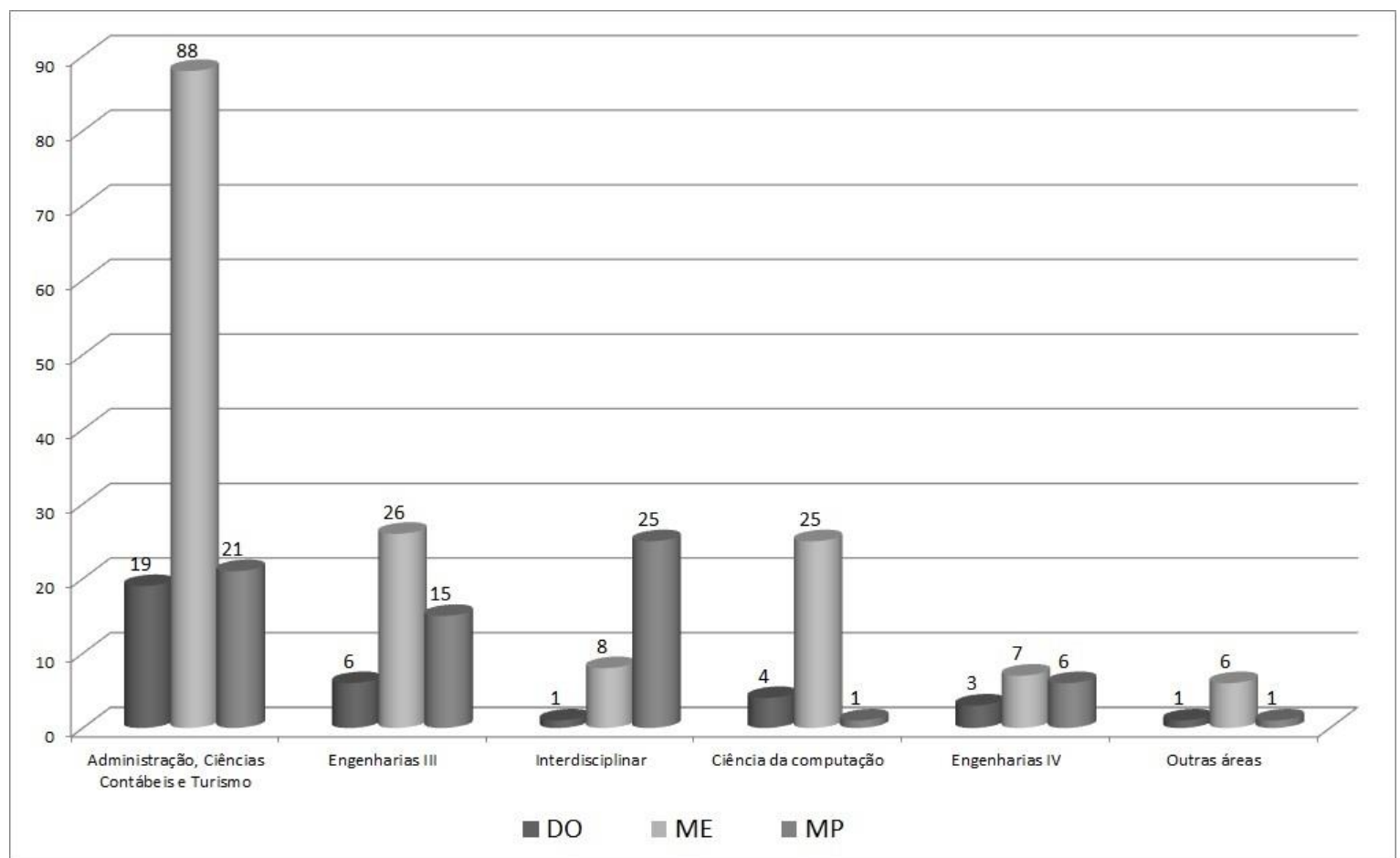

Ilustração 5 - Total de trabalhos das cinco áreas de conhecimento da CAPES com maior produção * Fonte: Autores da pesquisa

Das 48 áreas de conhecimento oficializadas pela CAPES no país, foram encontrados trabalhos em dez diferentes áreas (21\%). A temática 'governança e planejamento de $\mathrm{Tl}^{\prime}$ não é exclusiva de única área de conhecimento, com destaque para as Ciências Sociais Aplicadas, que engloba a área de avaliação da Administração, Ciências Contábeis e Turismo ' , com cerca de metade dos trabalhos, 128 no total (49\% do total). Esta área também tem a maior quantidade de trabalhos de doutorado e mestrado acadêmico, bem como a maior quantidade de trabalhos das três categorias temáticas analisadas.

Em seguida, as áreas de conhecimento Engenharias III (47) ii, Interdisciplinar (34) iii, Ciência da Computação (30) iv e Engenharias IV (16) ${ }^{\mathrm{v}}$, foram as áreas que também tiveram quantidade destacada de trabalhos. Verificou-se também a tendência de crescimento, ano a ano, considerando-se a série histórica analisada. A área Interdisciplinar também se destaca com o maior número de trabalhos quando considerado o nível mestrado profissional.

Com menos de três trabalhos, as áreas de conhecimento Ciência Política e Relações Internacionais (3) vi, Economia (2) vii, Educação (1) viii, Engenharias II (1) ix e Sociologia (1) ${ }^{x}$ também tiveram trabalhos identificados na coleta de dados efetuada.

\subsection{FREQUÊNCIA DE PALAVRAS E OBJETOS ENCONTRADOS NOS TÍTULOS}

A llustração 6 destaca a frequência das palavras evidenciados nos títulos das teses e dissertações analisadas na pesquisa. 
abordagem (11) administracao (8) linhamento (81) $_{\text {analise }}$ (22) aplicacao (8) avaliacao ${ }_{(16)}$ balanced (5) base (5) baseado (7) brasil (9) brasileiras (9) brasileiro (7) $\mathrm{CaSO}_{\text {(54) cobit (9) conhecimento (6) contexto (6) contribuicao (6) }}$ contribuicoes (5) corporativa (8) criticos (6) desempenho (9) desenvolvimento (7) diretrizes (5) empresas $_{(46)}$ ensino (12) estado (8) $^{\text {estrategia }}{ }_{(19) \text { estrategica }}^{(5)}$ estrategico ${ }_{(93)}$ estudo ${ }_{(61)}$ fatores (14) federal $_{(10)}$ gerenciamento $_{(21)}$ gestao $_{(49)}$ governanca ${ }_{(111)}$ impacto (11) implantacao $_{(10)}$ implementacao $_{(10)}$ informaCaO ${ }_{(135)}$ instituicao $_{(13)}$ instituicoes $_{(10)}$ itil (18) maturidade (7) mecanismos (5) metodologia (9) modelo ${ }_{(39)}$ negocio ${ }_{(37)}$ organizacao (5) organizacional (10) organizacoes (9) percepcao (5) planejamento (32) plano (8) praticas (24) processOS $_{(36)}$ projetos (10) proposta (10) publica (5) publico (5) relacoes (6) scorecard (5) servicos $_{(24)}$ setor $_{(25)}$ sistemas $_{(24) \text { software (9) sucesso (6) superior (9) }} \mathrm{teCnologia_{(128) }}$ ti $\mathbf{i}_{(105) \text { uso (6) }}$

Ilustração 6 - Frequência das palavras evidenciadas nos títulos

Fonte: Autores da pesquisa

Essa nuvem de palavras é uma forma de visualização que apresenta a frequência com que as palavras aparecem em determinado contexto (RIBEIRO et al., 2012), enfatizando assim as palavras com mais reincidência.

Além das palavras utilizadas para coleta dos trabalhos por meio da Plataforma Lattes, conforme descrito anteriormente no Quadro 1, como: alinhamento, estratégico, gestão, governança, informação, tecnologia e Tl; destacaram-se também palavras tais como: abordagem, análise, aplicação, avaliação, balanced, base, Brasil(eira/eiro), caso, conhecimento, contexto, contribuição(ões), corporativa, críticos, decisão, desempenho, desenvolvimento, diretrizes, empresa(s), ensino, estado, estudo, fatores, federal, impacto, implantação, implementação, instituição(ões), maturidade, metodologia, negócio(s), organização(ões/cional), percepção, práticas, processo(s), projeto(s), proposta, pública(o), relações, scorecard, serviços, setor, software, sucesso, superior e uso.

Quando analisados os objetos ou temas de pesquisa, foram identificados: empresas de vários ramos (energia, financeiro, indústria, software, telecomunicações, varejo, entre outros), de vários portes (pequeno, médio e grandes, além de arranjos produtivos locais), instituições de ensino e saúde (privados e públicos) e ainda governo (municipal, estadual e federal). De igual maneira, executivos de negócio e profissionais de TI também foram foco das pesquisas encontradas. Foram detectados ainda, a partir da análise dos títulos dos trabalhos analisados, temas relacionados para a elaboração de artefatos, processos, metodologias ou para análise de maturidade, seja da governança, seja do planejamento de TI.

Comparando-se ao artigo de Chagas et al. (2015), que tratou de GTI na administração pública, é percebido igual interesse em várias dissertações e teses observadas, que tinham foco em governo ou instituições federais e estaduais de ensino. Além disso, identificou-se lacunas voltadas à ausência de títulos relacionados à educação e pesquisa e ainda à produção científica ou sobre a interdisciplinaridade na temática.

\section{CONSIDERAÇÕES FINAIS}


A partir dos principais resultados auferidos na pesquisa, conclui-se que a temática governança e planejamento de TI tem sido assunto de interesse de pesquisa na pósgraduação stricto sensu no Brasil, notadamente pelo pleno crescimento no decorrer do período analisado. Metade dos estudos tem sido realizada na área da Administração, Ciências Contábeis e Turismo, mas também se verificou a ocorrência de trabalhos nas áreas de conhecimento: Engenharias III, Interdisciplinar, Ciência da Computação e Engenharias IV, entre outras, e que somadas, perfazem dez das 48 áreas de avaliação oficializadas pela CAPES.

Além disso, mais da metade dos trabalhos encontrados são oriundos de programas de excelente qualidade, com no mínimo nota 'Cinco' segundo a avaliação de 2013 realizada pela CAPES, sem considerar os cursos de mestrado profissional que têm critérios de avaliação diferenciados.

Dentre os principais resultados, foram identificados 263 trabalhos concluídos, sendo 34 teses, 160 dissertações acadêmicas e 69 dissertações de mestrado profissional. Percebeuse tendência de crescimento no decorrer do período analisado. Quanto ao ano mais profícuo, destaca-se o ano de 2012. Já quanto às categorias de análise, destaca-se a governança de $\mathrm{TI}$ com maior produção verificada. Com 259 alunos egressos, 104 programas em 67 diferentes IES e 176 orientadores, a Universidade Católica de Brasília apresentou a maior quantidade de trabalhos, sendo João Souza Neto o orientador mais profícuo na produção verificada. As instituições particulares sem fins lucrativos, a região Sudeste e o estado de São Paulo, em especial, se destacaram das demais unidades analisadas. A nota 'Quatro' foi a nota mais encontrada nos cursos de mestrado analisados, e nota 'Sete' foi a nota mais encontrada nos cursos de doutorado prospectados, segundo avaliação da CAPES divulgada em 2013.

Algumas das principais palavras encontradas nos títulos foram: análise, caso, empresas, estudo, modelo, negócio, práticas, processos, serviços e setor. Ademais, quando analisados os objetos ou temas de pesquisa, foram identificados: governo, empresas de vários ramos e portes e ainda instituições de ensino e saúde. De igual maneira, executivos de negócio e profissionais de TI também foram foco das pesquisas encontradas. Foram detectados ainda, a partir da análise dos títulos dos trabalhos, temas relacionados à elaboração de artefatos, processos, metodologias ou análise de maturidade, seja da governança, seja do planejamento de TI.

Quando comparado com outros trabalhos bibliométricos, observou-se que a maioria das instituições e pesquisadores da amostra coletada para este trabalho, igualmente participam em congressos científicos específicos, o que reflete no avanço nesta área com o compromisso de socializar o conhecimento construído no stricto sensu a partir de dissertações e teses.

Como contribuição deste trabalho aos pesquisadores sobre a temática apresentada, são apresentados os resultados dos programas de pós-graduação disponíveis no país, que tem se dedicado às pesquisas destes temas em específico. Além dos tradicionais programas da área de Administração, outras áreas, tais como a Engenharia III, com o exemplo do curso de Engenharia da Produção; a Ciência da Computação, com programas de mesma nomenclatura e ainda a área Interdisciplinar, com o programa de Informática e Gestão do Conhecimento, entre outros resultados auferidos na pesquisa, compõem algumas das possibilidades encontradas. Outrossim, a ausência de títulos relacionados à educação e pesquisa, produção científica, sobre a interdisciplinaridade na temática analisada, foram algumas lacunas de trabalhos de stricto sensu não encontrados nesta pesquisa. 
A maior dificuldade deste trabalho deu-se durante a extração manual das informações do Currículo Lattes, conforme exposto por Autran et al. (2015). Por esse motivo, além da demora na extração, esta é suscetível a eventuais erros oriundos do lançamento das informações na Plataforma Lattes.

Uma das limitações da presente pesquisa volta-se à impossibilidade de ter sido realizado um detalhamento maior sobre os dados coletados, a partir, por exemplo, da análise da rede social dos pesquisadores envolvidos, que teria mais sentido, ao se identificar a partir dos orientadores e egressos destes cursos onde e com quem publicam em periódicos. Neste sentido, outra possível indicação de trabalho futuro seria a identificação de autores e obras mais citadas, realização de análise da adequação entre a natureza do estudo (exploratória, descritiva ou explanatória) e a metodologia empregada (pesquisa quantitativa, survey, experimental e qualitativa, estudo de caso, pesquisa-ação). Outros possíveis desdobramentos a serem indicados são: identificar a relação dos objetivos da pesquisa e os resultados obtidos em cada trabalho, bem como a realização desta mesma pesquisa com outros temas pertinentes, como por exemplo: gestão de projetos, gestão da informação e gestão do conhecimento, entre outros assuntos.

\section{REFERÊNCIAS}

ALBERTIN, A. L.; MOURA, R. M. Administração de informática: funções e fatores críticos de sucesso. São Paulo: Atlas, 2009.

ALI, S. M.; SOOMRO, T. R.; BROHI, M. N. Mapping information technology infrastructure library with other information technology standards and best practices. Journal of Computer Science. v. 9, n. 9. p. 1190-1196, 2013.

ALMEIDA, L. M; SANTOS, E. M. Alinhamento estratégico entre negócio e Tecnologia da Informação: um estudo bibliométrico em eventos científicos brasileiros no período de 20092013. In: Conferência Internacional sobre Sistemas de Informação e Gestão de Tecnologia, XI, São Paulo, 2014. Anais... São Paulo, 2014.

ANPAD - Associação Nacional de Pós-graduação e Pesquisa em Administração. Sobre as divisões acadêmicas da ANPAD. Rio de Janeiro: ANPAD, 2016. Disponível em: <http://www.anpad.org.br/ anpad/sobre_div_academicas.php>. Acesso em: 11 jul. 2016.

AUtRAN, M. M. M.; BORGES, M. M.; MENA-CHALCO, J. M.; PINHEIRO, V. G. Perfil de produção acadêmica dos programas brasileiros de pós-graduação em ciência da informação 2008-2012. Perspectivas em Ciência da Informação. v.20, n.4, p.57-78, out./dez. 2015.

AVELINO, B. C; BARBOSA, R. R.; SOARES, I. P. Produção científica na área de sistemas de tecnologia e sistemas de informação: uma análise bibliométrica. In: Conferência Internacional sobre Sistemas de Informação e Gestão de Tecnologia, IX, São Paulo, 2012, Anais... São Paulo, 2012.

BERMEJO, P.; TONELLI, A.; ZAMBALDE, A. Developing IT Governance in Brazilian Public Organizations. International Business Research. v. 7, n. 3, p. 101-114, 2014. 
CAPES. Dados cadastrais dos programas. Brasília: CAPES, 2015. Disponível em: <https://sucupira.capes.gov.br/sucupira>. Acesso em: 15 dez. 2015.

CHAGAS, V.; SUN, V.; REINHARD, N. Estudo bibliométrico sobre a governança de TI na administração pública. In: Encontro de Administração da Informação, V, Brasília, 2015. Anais... Rio de Janeiro, ANPAD, 2015.

CHUEKE, G. V.; AMATUCCI, M. O que é bibliometria? Uma introdução ao Fórum. Internext. v. 10, n. 2, p. 1-5, mai/ago. 2015.

CNPq - Conselho Nacional de Desenvolvimento Científico e Tecnológico. Plataforma Lattes. Brasília: CNPq, 2015. Disponível em: <http://lattes.cnpq.br>. Acesso em: 15 dez. 2015.

CONTECSI - Congresso Internacional de Gestão da Tecnologia e Sistemas de Informação. Sobre o CONTECSI. São Paulo: USP, 2016. Disponível em: <http://www.contecsi.fea.usp.br/?q=pt-br/node/13>. Acesso em: 11 jul. 2016.

CÔRTES, P. L. A importância da literatura cinzenta disponível na internet para as áreas de Ciências Contábeis e Administração de Empresas. Revista Brasileira de Gestão de Negócios. v. 8, n. 20, p. 13-22, jan./abr. 2006.

COSTA, R. F.; ROSINI, A. M. Estudo do impacto da governança de tecnologia da informação no desempenho das empresas brasileiras: uma análise a partir da perspectiva dos executivos, usuários e membros de equipes de TI. Future Studies Research Journal. v. 7, n.2, p.155-176, jul-dez. 2015.

FERNANDES, A. A.; ABREU, V. F. Implantando a governança de TI: da estratégia à gestão dos processos e serviços. 4 ed. Rio de Janeiro: Brasport, 2014.

FLICK, U. Introdução à metodologia de pesquisa: um guia para iniciantes. São Paulo: Penso, 2013.

FREITAS, H. M. R.; BECKER, J. L.; MARCOLIN, C. B. Uma visão sobre a pesquisa acadêmica em SI no Brasil: 1994 a 2013. In: Encontro da ANPAD, XXXVIII, Rio de Janeiro, 2014. Anais... Rio de Janeiro: ANPAD, 2014.

GONÇALVES, A. P.; GASPAR, M. A.; CARDOSO, M. V. Governança de tecnologia da informação: uma análise do nível de maturidade em empresas atuantes no Brasil. Revista de Gestão e Projetos. v. 7, n. 1. jan/abr. 2016.

GRAEML, A. R.; MACADAR, M. A.; GUARIDO FILHO, E. R.; ROSSONI, L. Redes sociais e intelectuais em administração da informação: uma análise cientométrica do período 19972006. Inf. \& Soc.:Est. João Pessoa, v.20, n.1, p. 95-110, jan./abr. 2010.

ISACA. Modelo corporativo para governança e gestão de TI da organização: COBIT 5 Framework. Rolling Meadows: ISACA, 2012.

ITGI - Information Technology Governance Institute. About IT Governance. 2011. Disponível em <http://www.itgi.org>. Acesso em: 10 mai. 2016.

KAPLAN, R.; NORTON, D. Mapas estratégicos. Rio de Janeiro: Campus, 2004. 
LOMBARDI, R.; GIUDICE, M. D.; CAPUTO, A.; EVANGELISTA, F.; RUSSO, G. Governance and assessment insights in information technology: the Val IT model. Journal of the Knowledge Economy. 7:292-308, 2016.

LUFTMAN, J.; LYYTINEN, K; ZVI, T. Enhancing the measurement of information technology (IT) business alignment and its influence on company performance. Journal of Information Technology, p. 1-21, Sep. 2015.

LUFTMAN, J.; ZADEH, H. S.; DERKSEN, B.; SANTANA, M. et al. Key information technology and management issues 2012-2013: an international study. Journal of Information Technology, v. 28, n. 4, p. 354-366, Dec. 2013.

LUNARDI, G. L.; BECKER, G. L.; MAÇADA, A. C. G. Impacto da Adoção de Mecanismos de Governança de Tecnologia de Informação (TI) no desempenho da Gestão da TI: uma análise baseada na percepção dos executivos. Revista de Ciências da Administração. v. 12, n. 28, p. 11-39, set/dez 2010.

MAGALHÃES, F. L. F.; GASPAR, M. A.; CAMPOS, J. G. F. Planejamento estratégico de tecnologia da informação: análise de conceitos, frameworks e processos apresentados em livros publicados no Brasil. In: Conferência Internacional sobre Sistemas de Informação e Gestão de Tecnologia, XIII, São Paulo, 2016, Anais... São Paulo, CONTECSI, 2016.

MARQUES, E. V.; MOTA, A. F. Governança da tecnologia da informação: um estudo bibliométrico em eventos e periódicos brasileiros. Revista Eletrônica de Sistemas de Informação, v. 12, n. 2, 2013.

MEC - Ministério da Educação. Instituições de educação superior e cursos cadastrados. Brasília: MEC, 2015. Disponível em: <http://emec.mec.gov.br>. Acesso em: 01 mar. 2016.

MORAES, A. F.; OLIVEIRA, T. M. Experiências relacionadas ao levantamento de teses e dissertações. Inf. \& Soc.:Est. v. 20, n. 1, p. 73-81, jan./abr. 2010.

OLUTOYIN, O.; FLOWERDAY, S. Successful IT governance in SMES: An application of the Technology-Organisation-Environment theory. South African Journal of Information Management. v. 18, n. 1, p. 1-8, 2016.

PALMISANO, A.; ROSINI, A. M. Administração de sistemas de informação e a gestão do conhecimento. São Paulo: Cengage Learning, 2012.

RASERA, M.; WALTER, S. A.; CHEROBIM, A. P. M. S. C.; CUNHA, M. A. Governança de tecnologia de informação: um estudo bibliométrico e sociométrico da produção científica brasileira no Enanpad de 2004-2009. In: SEMEAD, XIII, São Paulo, 2010. Anais... São Paulo: FEA-USP, 2010.

RIBEIRO, H. C. M.; MACHADO JÚNIOR, C.; SOUZA, M. T. S.; CAMPANÁRIO, M. A.; CORRÊA, R. Governança corporativa: um estudo bibliométrico da produção científica das dissertações e teses brasileiras. Contabilidade, Gestão e Governança. v. 15, n. 3, p. 52-70, set./dez. 2012.

SELIG, G. J. IT Governance - an integrated framework and roadmap: how to plan, deploy and sustain for improved effectiveness. Journal of International Technology and Information Management. v. 25, n. 1, p. 55-76, 2016. 
SEMEAD - Seminários em Administração. Áreas científicas temáticas. São Paulo: USP, 2016. Disponível em: <http://semead.com.br>. Acesso em: 11 jul. 2016.

TEODORO, A. N.; PRVEYBILOVICZ, E.; CUNHA, M. A. Governança de tecnologia da informação: uma investigação sobre a representação do conceito. Revista de Administração. v. 49, n. 2, p. 307-321, abr./jun. 2014.

VALLE, A. B. Gestão estratégica da tecnologia da informação. 2 ed. Rio de Janeiro: FGV, 2015.

WEILL, P.; ROSS, J. Governança de TI: como administrar os direitos decisórios de TI na busca por resultados superiores. São Paulo: Makron Books, 2006.

WOLMARAUS, A.; KRUGER, N; CROFT, N. Company divestment: applicability of existing IT governance frameworks. International Journal of Computing and Informatics. V. 1, n. 2, p. 30-35, May 2016.

\footnotetext{
${ }^{i}$ Exemplos de alguns programas encontrados na área da Administração foram: Administração, Administração e negócios, Ciências Contábeis.

ii Exemplos de alguns programas encontrados na área Engenharias III foram: Engenharia da produção, Gestão e Tecnologia em Sistemas Produtivos, Sistemas de Gestão, Engenharia Mecânica.

iii Exemplos de alguns programas encontrados na área da Interdisciplinar foram: Gestão do conhecimento e da tecnologia da informação, Informática, Sistemas de Informação e Gestão do Conhecimento.

iv Exemplos de alguns programas encontrados na área da Ciência da computação foram: Ciência da computação, Informática, Engenharia de Sistemas e Computação, Sistemas de Informação.

${ }^{\vee}$ Exemplos de alguns programas encontrados na área das Engenharias IV: Engenharia Elétrica, Gestão de Redes de Telecomunicações.

${ }^{v i}$ Exemplos de alguns programas encontrados na área da Ciência Política e Relações Internacionais: Ciências militares.

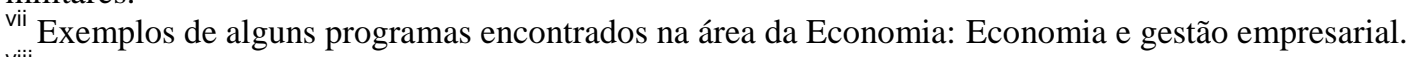

viii Exemplos de alguns programas encontrados na área da Educação: Educação.

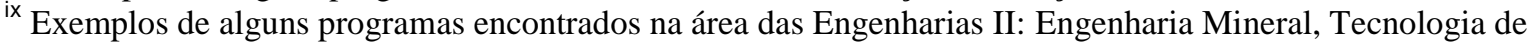
processos químicos e bioquímicos.

${ }^{\mathrm{x}}$ Exemplos de alguns programas encontrados na área da Sociologia: Ciências Sociais.
} 